\title{
Apropos: critical analysis of molluscicide application in schistosomiasis control programs in Brazil
}

\author{
Hongjun Li and Wei Wang ${ }^{2,3,4,5^{*}}$ (D)
}

\begin{abstract}
Schistosomiasis is a snail-transmitted infectious disease affecting over 200 million people worldwide. Snail control has been recognized as an effective approach to interrupt the transmission of schistosomiasis, since the geographic distribution of this neglected tropical disease is determined by the presence of the intermediate host snails. In a recent Scoping Review published in Infectious Diseases of Poverty, Coelho and Caldeira performed a critical review of using molluscicides in the national schistosomiasis control programs in Brazil. They also described some chemical and plant-derived molluscicides used in China. In addition to the molluscicides described by Coelho and Caldeira, a large number of chemicals, plant extracts and microorganisms have been screened and tested for molluscicidal actions against Oncomelania hupensis, the intermediate host of Schistosoma japonicum in China. Here, we presented the currently commercial molluscicides available in China, including 26\% suspension concentrate of metaldehyde and niclosamide (MNSC), 25\% suspension concentrate of niclosamide ethanolamine salt (SCNE), 50\% niclosamide ethanolamine salt wettable powder (WPN), 4\% niclosamide ethanolamine salt dustable powder (NESP), 5\% niclosamide ethanolamine salt granule (NESG) and the plant-derived molluscicide "Luowei". These molluscicides have been proved to be active against $O$. hupensis in both laboratory and endemic fields, playing an important role in the national schistosomiasis control program of China. Currently, China is transferring its successful experiences on schistosomiasis control to African countries. The introduction of Chinese commercial molluscicides to Africa, with adaptation to local conditions, may facilitate the progress towards the elimination of schisosomiasis in Africa.
\end{abstract}

Keywords: Schistosomiasis, Oncomelania hupensis, Molluscicide, 26\% suspension concentrate of metaldehyde and niclosamide, 25\% suspension concentrate of niclosamide ethanolamine salt, 50\% niclosamide ethanolamine salt wettable powder, 4\% niclosamide ethanolamine salt dustable powder, 5\% niclosamide ethanolamine salt granule, Luowei

\section{Multilingual abstract}

Please see Additional file 1 for translations of the abstract into the six official working languages of the United Nations.

\section{Introduction}

Schistosomiasis, caused by the blood fluke parasites of Schistosoma genus, is a snail-transmitted infectious disease

\footnotetext{
* Correspondence: wangwei@jipd.com

${ }^{2}$ Key Laboratory of National Health and Family Planning Commission on Parasitic Disease Control and Prevention, 117 Yangxiang, Meiyuan, Wuxi City, Jiangsu Province 214064, China

${ }_{3}^{3}$ Jiangsu Provincial Key Laboratory on Parasites and Vector Control

Technology, 117 Yangxiang, Meiyuan, Wuxi City, Jiangsu Province 214064,

China

Full list of author information is available at the end of the article
}

affecting over 200 million people worldwide [1]. Since the geographic distribution of this neglected tropical disease is determined by the presence of the intermediate host snails of the parasite, snail control is considered to be effective to interrupt the transmission of the disease [2]. A recent quantitative analysis of schistosomiasis control outcomes captured from 83 countries and territories over the past 100 years, showed that the extensive snail control contributed to a reduction of schistosomiasis prevalence by $92 \%$, while the control programs with little or no snail control interventions achieved a 37\% reduction, which highlights the critical role of snail control in the schistosomiasis control programs [3].

In a recent Scoping Review published in in the journal Infectious Diseases of Poverty, Coelho and Caldeira [4] 
performed a critical review of using molluscicides in the national schistosomiasis control programs in Brazil. They also described some chemical and plant-derived molluscicides used in China. From the initiation of the national schistosomiasis control program until now, the national schistosomiasis control strategy of China has shifted from transmission control strategy based on snail control between mid-1950s and early 1980s, praziquantel chemotherapy based-morbidity control strategy during the period from mid-1980s through 2003, to the current integrated control strategy since 2004, and snail control has been an important part of the national schistosomiasis control strategy throughout the control programs [5]. Currently, molluscicide treatment remains the predominant approach for snail control in China [6]. In addition to the molluscicides described by Coelho and Caldeira, a large number of chemicals, plant extracts and microorganisms have been screened and evaluated for molluscicidal actions against Oncomelania hupensis, the intermediate host of S. japonicum. Here, we summarized the currently commercial molluscicides available in China, which have been proved to be active against $O$. hupensis in both laboratory and endemic fields.

\section{$26 \%$ suspension concentrate of metaldehyde and niclosamide (MNSC)}

MNSC, a mixture of 25\% niclosamide and $1 \%$ metaldehyde, is prepared by grinding niclosamide, metaldehyde, glycerol, sodium carboxymethyl cellulose, sodium benzoate and distilled water in a ball miller to yield a suspension formulation. In the laboratory, immersion with MNSC at $0.125 \mathrm{mg} / \mathrm{L}$ and higher concentrations for $24 \mathrm{~h}$ achieved $100 \%$ snail mortality, with a $24 \mathrm{~h} \mathrm{LC}_{50}$ of $0.058 \mathrm{mg} / \mathrm{L}$ and a $48 \mathrm{~h} \mathrm{LC}_{50}$ of $0.044 \mathrm{mg} / \mathrm{L}$. Spraying with MNSC at $2 \mathrm{~g} / \mathrm{m}^{2}$ resulted in 94, 100 and $100 \%$ snail mortality at 1, 3, and 7 days, respectively [7]. In the marshland and lake regions, the field immersion test showed 97.5-100\%, 98.89-100\% and $100 \%$ snail mortality following treatment with MNSC at $2 \mathrm{~g} / \mathrm{m}^{3}$ for 24,48 and $72 \mathrm{~h}$, while the field spraying test revealed $67.81-95.53 \%, 72.8-89.68 \%$, and $86.67-100 \%$ snail mortality following treatment with MNSC at $2 \mathrm{~g} / \mathrm{m}^{2}$ for 1 , 3 , and 7 days, respectively [7]. In the mountainous regions, spraying with MNSC at $6 \mathrm{~g} / \mathrm{m}^{2}$ resulted in $92.88-94.46 \%$ snail mortality at 7 days, $90.47-93.79 \%$ at 15 days and $88.68-94.27 \%$ at 30 day, respectively [8]. Compared with the $50 \%$ wettable powder of niclosamide ethanolamine salt (WPN), the first-choice chemical molluscicide used for snail control in China since 1990s on the recommendation of WHO [9], MNSC reduces the toxicity of niclosamide to the environment and fish [7]; however, the exact effect of MNSC on the environment and the mechanisms underlying the molluscicidal efficacy of the drug against $O$. hupensis snails remain to be investigated.
In addition, MNSC was reported to be active against Lymnaea species [10], and 25\% suspension concentrate of niclosamide (SCN) has shown toxicity to both adult and juvenile Biomphalaria glabrata [11]. These exciting findings encourage the investigations of the molluscicidal efficacy of 26\% MNSC against Biomphalaria spp. and Bulinus spp..

\section{$25 \%$ suspension concentrate of niclosamide ethanolamine salt (SCNE)}

SCNE is a novel suspension formulation of niclosamide which contains $25 \%$ niclosamide ethanolamine salt. In the laboratory, immersion with SCNE at $0.125 \mathrm{mg} / \mathrm{L}$ and higher doses for $24 \mathrm{~h}$ and a longer period of time resulted in $100 \%$ snail mortality, with $0.058,0.044$ and $0.039 \mathrm{mg} / \mathrm{L}$ for 24,48 , and $72 \mathrm{~h} \mathrm{LC}_{50}$ values, respectively, and spraying with SCNE at 1 to $8 \mathrm{~g} / \mathrm{m}^{2}$ achieved 90-100\% snail mortality at 1 day, $97-100 \%$ at 3 days, and $99-100 \%$ at 7 days, respectively, depending on drug doses [12]. In a marshland and lake region, the field immersion test showed $100 \%$ snail mortality following the treatment with SCNE at $2 \mathrm{~g} / \mathrm{m}^{3}$ for 24,48 , or $72 \mathrm{~h}$, and the field spraying test revealed $74.51-88.81 \%$ snail mortality at 1 day, $80.34-98.26 \%$ at 3 days and $87.38-$ $100 \%$ at 7 days depending on the drug doses given ( 1 to $8 \mathrm{~g} / \mathrm{m}^{2}$ ) [12]. This formulation provides a novel choice of chemical molluscicides for the field application in the endemic foci of China; however, further studies are required to investigate the environmental toxicity and the mechanisms of action of SCNE.

\section{WPN}

With the initiation of the World Bank Loan Project for Schistosomiasis Control in China since 1992, WPN was introduced and currently it is the most widely used chemical molluscicide in China [13]. The sensitivity of $O$. hupensis to WPN varies in the schistosomiasis-endemic regions of China [14], and a recent meta-analysis showed 77\% (95\% CI: 68 to 86\%), 83\% (95\% CI: 77 to 89\%) and 88\% (95\% CI: 82 to $92 \%$ ) snail mortality after spraying WPN at a dose of $2 \mathrm{~g} / \mathrm{m}^{2}$ for 3,7 and 15 days in the marshland regions [15]. Excitingly, no evidence of resistance to WPN has been detected in O. hupensis after more than 2 decades of repeated, extensive application in the main endemic foci of China [16].

Recently, de Novo transcriptome analysis revealed 254 differentially expressed unigenes in WPN-treated $O$. hupensis snails, which were associated with cell structure defects and inhibition of neurohumoral transmission and energy metabolism that may cause snail death [17]. In addition, WPN treatment resulted in damages to cell structures and organelles of $O$. hupensis snails, suggesting the suppression of the movement ability and effects on liver and energy metabolism; in parallel, activities of 
carbohydrate metabolism-associated enzymes were inhibited, and activities of stress response-associated enzymes were increased followed by a reduction to lower levels than those of the $\mathrm{H}_{2} \mathrm{O}$-treated group [18]. This shift of carbohydrate metabolism patterns led to insufficient energy supply and lactic acid accumulation [18]. Variations of nitric oxide synthase (NOS), alanine aminotransferase (ALT), and superoxide dismutase (SOD) during the WPN treatment suggested a stress response of $O$. hupensis snail to the molluscicide at early stages and later fatal damage in the liver and the nervous system [18]. However, the environmental issues related to the use of WPN have not been clearly demonstrated to date.

\section{4\% niclosamide ethanolamine salt dustable powder (NESP)}

Although WPN is highly active against $O$. hupensis, the use of this niclosamide formulation requires water, which limits its application in the endemic regions lacking water [19]. To overcome this problem, a novel formulation of niclosamide, NESP, was developed in 2003, which contains $4 \%$ niclosamide ethanolamine salt [20]. Laboratory test showed a $0.197 \mathrm{~g} / \mathrm{m}^{2} 24 \mathrm{~h} \mathrm{LC}_{50}$ for NESP against $O$. hupensis [21], and the meta-analysis showed 81\% (95\% CI: 65 to 93\%), 90\% (95\% CI: 83 to 95\%) and 94\% (95\% CI: 91 to $97 \%)$ snail mortality after treatment with NESP at a $2 \mathrm{~g} / \mathrm{m}^{2}$ used dose of niclosamide for 3, 7 and 15 days in the marshland regions [15]. NESP has been considered an effective supplement of currently available chemical molluscicides in China [22]; however, the powder may drift, which may result in potential environmental pollution.

\section{$\mathbf{5 \%}$ niclosamide ethanolamine salt granule (NESG)}

The use of niclosamide suspension formulations requires water, and the powder formulation suffers from the drug drift and the resultant environmental pollution, as well as potential damages to workers spraying the powder. NESG was therefore developed in order to overcome these problems [23]. Laboratory test showed that spraying with NESG at $0.5,1$ and $2 \mathrm{~g} / \mathrm{m}^{2}$ resulted in $85-98 \%$ snail mortality at 1 day, $93-99 \%$ at 3 days and $96-100 \%$ at 7 days, respectively, depending on drug doses [23]. In the marshland region, 7 days treatment with $2 \mathrm{~g} / \mathrm{m}^{2}$ NESG achieved $85.42 \%$ snail mortality and a $93.1 \%$ reduction in the density of living snails [24], and in the mountainous region, spraying with NESG at $2 \mathrm{~g} / \mathrm{m}^{2}$ resulted in $72.41 \%$ snail mortality at 7 days, $74.61 \%$ at 15 days and $73.24 \%$ at 30 day, and reduced the density of living snails by $72.26 \%$ at 7 days, $74.09 \%$ at 15 days and $75.91 \%$ at 30 day, respectively [25]. NESG is a breakthrough niclosamide formulation of chemical molluscicides in China, and this agent greatly expands the application range of niclosamide formulations. Further studies to investigate the environmental toxicity of this formulation seem justified.

\section{"Luowei", a plant-derived molluscicide}

"Luowei" is a pentacyclic triterpenoid extracted from the seed of the plant Camellia oleifera. Laboratory immersion test showed 93.33, 96.67 and 100\% snail mortality at 24, 48 and $72 \mathrm{~h}$ after treatment with "Luowei" at a dose of $2.5 \mathrm{~g} / \mathrm{L}$, and 96.67, 100 and $100 \%$ snail mortality at 24,48 , and $72 \mathrm{~h}$ after treatment with "Luowei" at $5 \mathrm{~g} / \mathrm{L}$, and laboratory spraying test revealed $70,76.67$ and $83.33 \%$ snail mortality at 1,3 and 7 days following treatment with "Luowei" at $2.5 \mathrm{~g} / \mathrm{m}^{2}$, and $90,96.67$, and $100 \%$ snail mortality at 1,3 , and 7 days following treatment with "Luowei" at $5 \mathrm{~g} / \mathrm{m}^{2}$ [26]. In addition, the field test showed that spraying with "Luowei" at $5 \mathrm{~g} / \mathrm{m}^{2}$ achieved $81.57 \%$ snail mortality at 1 day, $84.98 \%$ at 3 days, $84.68 \%$ at 7 days, and $86.53 \%$ at 15 days in the marshland and lake regions [27]; $81.44 \%$ snail mortality at 1 day, $86.95 \%$ at 3 days, $90.3 \%$ at 7 days, and $90.26 \%$ at 15 din the plain regions [28]; 56.47\% snail mortality at 1 day, $57.32 \%$ at 3 days, $90.58 \%$ at 7 days and $93.41 \%$ at 15 days in the hilly regions [29]; and $69.55 \%$ snail mortality at 1 day, $78.09 \%$ at 3 days, $88.39 \%$ at 7 days and $87.39 \%$ at 15 days in the mountainous regions, respectively [30]. Toxicity testing showed a $0.15 \mathrm{mg} / \mathrm{L}$ ( $95 \% \mathrm{CI}$ : 0.14 to $0.17 \mathrm{mg} / \mathrm{L}$ ) $\mathrm{LC}_{50}$ for "Luowei" in the Zebra fish, $>60 \mathrm{mg} / \mathrm{kg} \mathrm{LC}$ in in Coturnix coturnix, a $6.28 \mathrm{mg} / \mathrm{L}(95 \%$ CI: 3.53 to $11.2 \mathrm{mg} / \mathrm{L}) 96 \mathrm{~h} \mathrm{LC}_{50}$ in the freshwater shrimps [31], and an acute inhalation $\mathrm{LC}_{50}$ of $>5000 \mathrm{mg} /$ $\mathrm{m}^{3}$ in rats [32]. However, the mechanisms of action and environmental assessment of this plant-derived molluscicide have not been reported until now.

In addition, "Luowei" was found to be active against Pomacea canaliculata [33], and the molluscicidal efficacy of "Luowei" against Biomphalaria and Bulinus is under evaluation.

\section{Conclusions}

During the past two decades, a large number of novel molluscicides have been screened and developed in China, and many of them have been made commercial. In addition to chemical and plant-derived agents, the molluscicidal action of microorganisms against $O$. hupensis has been recently paid more and more attention [34-36].

Currently, China is transferring its successful experiences on schistosomiasis control to African countries [37, 38]. The introduction of Chinese commercial molluscicides, with adaptation to African local conditions, may facilitate the progress towards the elimination of schisosomiasis in Africa [39]. 


\section{Additional file}

Additional file 1: Multilingual abstract in the six official working languages of the United Nations. (PDF 688 kb)

\section{Abbreviations}

MNSC: $26 \%$ suspension concentrate of metaldehyde and niclosamide NESG: $5 \%$ niclosamide ethanolamine salt granule; NESP: $4 \%$ niclosamide ethanolamine salt dustable powder; SCN: $25 \%$ suspension concentrate of niclosamide; SCNE: $25 \%$ suspension concentrate of niclosamide ethanolamine salt; WPN: 50\% niclosamide ethanolamine salt wettable powder

\section{Acknowledgements}

We would like to express our sincere thanks to anonymous reviewers for their kind comments to improve our manuscript.

\section{Funding}

This study was supported by the grant from Jiangsu Department of Health (grantno. Q201404).

\section{Availability of data and materials}

The data supporting the findings in this paper can be provided for free by contact with the corresponding author.

\section{Authors' contributions}

WW conceived and designed the study. HJL collected literatures. HJL drafted the manuscript. WW revised and finalized the manuscript. Both authors read and approved the final version of the manuscript.

\section{Competing interests}

The authors declare that they have no competing interests.

\section{Consent for publication}

Not applicable.

\section{Ethics approval and consent to participate}

Not applicable.

\section{Author details}

'Weifang Maternity and Child Care Hospital, 407 Qingnian Road, Weicheng District, Weifang City, Shandong Province 261011, China. ${ }^{2}$ Key Laboratory of National Health and Family Planning Commission on Parasitic Disease Control and Prevention, 117 Yangxiang, Meiyuan, Wuxi City, Jiangsu Province 214064, China. ${ }^{3}$ Jiangsu Provincial Key Laboratory on Parasites and Vector Control Technology, 117 Yangxiang, Meiyuan, Wuxi City, Jiangsu Province 214064, China. ${ }^{4}$ Jiangsu Institute of Parasitic Diseases, 117 Yangxiang, Meiyuan, Wuxi City, Jiangsu Province 214064, China. ${ }^{5}$ School of Public Health, Fujian Medical University, No. 88 Jiaotong Road, Fuzhou City, Fujian Province 350004, China.

\section{Received: 29 July 2016 Accepted: 17 January 2017}

Published online: 07 March 2017

\section{References}

1. Colley DG, Bustinduy AL, Secor WE, King CH. Human schistosomiasis. Lancet 2014;383:2253-64

2. Lardans $V$, Dissous C. Snail control strategies for reduction of schistosomiasis transmission. Parasitol Today. 1998;14:413-7.

3. Sokolow SH, Wood CL, Jones IJ, Swartz SJ, Lopez M, Hsieh MH, Lafferty KD, Kuris AM, Rickards C, De Leo GA. Global assessment of schistosomiasis control over the past century shows targeting the snail intermediate host works best. PLoS Negl Trop Dis. 2016;10:e0004794

4. Coelho P, Caldeira RL. Critical analysis of molluscicide application in schistosomiasis control programs in Brazil. Infect Dis Poverty. 2016:5:57.

5. Collins C, Xu J, Tang S. Schistosomiasis control and the health system in PR China. Infect Dis Poverty. 2012:1:8

6. Li ZJ, Ge J, Dai JR, Wen LY, Lin DD, Madsen H, Zhou XN, Lv S. Biology and control of snail intermediate host of Schistosoma japonicum in the People's Republic of China. Adv Parasitol. 2016;92:197-236.
7. Bao ZP, Cao CL, Dai JR, Liu JB, Li GP, Guo JD, Guo JG. Evaluation on molluscicidal effect of suspension concentrate of metaldehyde and niclosamide. Chin J Schisto Control. 2011;23:48-53, (in Chinese).

8. Li BG, Li WB, Feng XG, Dong Y, Wu MS, Shao ZT, Mu LX, Tian SH, Li P, Gao $L P$, Xiong $K$, Dong $X Q$. Molluscicidal effect of suspension concentrate of metaldehyde and niclosamide in fields of mountainous areas in Yunnan Province. Chin J Schisto Control. 2012;24:564-6, (in Chinese).

9. Dai JR, Wang W, Liang YS, Li HJ, Guan XH, Zhu YC. A novel molluscicidal formulation of niclosamide. Parasitol Res. 2008;103:405-12.

10. Wang SW, Wang HY, Luo BR, Li KR, Liu YH, Zhao SH, Yang H, Li TM Molluscicidal effect of WPN and MNSC on Lymnaea. Chin J Schisto Control. 2013;25:61-3, (in Chinese).

11. Dai JR, Coles GC, Wang W, Liang YS. Toxicity of a novel suspension concentrate of niclosamide against Biomphalariaglabrata. Trans Roy Soc Trop Med Hyg. 2010;104:304-6.

12. Dai JR, Li HJ, Shen XH, Wang W, Tao YH, Chen XP, Liang YS. Study on molluscicidal effect of suspension concentrate of niclosamide ethanolamine salt. Chin J Schisto Control. 2009;21:83-6, (in Chinese).

13. Xianyi $C$, Liying $W$, Jiming $C$, Xiaonong $Z$, Jiang $Z$, Jiagang $G$, Xiaohua $W$, Engels D, Minggang C. Schistosomiasis control in China: the impact of a 10-year World Bank Loan Project (1992-2001). Bull World Health Organ. 2005;83:43-8.

14. Dai J, Li Y, Wang W, Xing Y, Qu G, Liang Y. Sensitivity of Oncomelania hupensis to niclosamide: a nation-wide survey in China. Int J Environ Res Public Health. 2014;11:3086-95.

15. Yang GJ, Li W, Sun LP, Wu F, Yang K, Huang YX, Zhou XN. Molluscicidal efficacies of different formulations of niclosamide: result of meta-analysis of Chinese literature. Parasit Vectors. 2010:3:84

16. Dai JR, Li YZ, Wang W, Xing YT, Qu GL, Liang YS. Resistance to niclosamide in Oncomelania hupensis, the intermediate host of Schistosoma japonicum: should we be worried? Parasitology. 2015;142:332-40.

17. Zhao QP, Xiong T, Xu XJ, Jiang MS, Dong HF. De Novo transcriptome analysis of Oncomelania hupensis after molluscicide treatment by next-generation sequencing: implications for biology and future snail interventions. PLoS One. 2015;10:e0118673

18. Xiong T, Zhao QP, Xu XJ, Liu R, Jiang MS, Dong HF. Morphological and enzymatical observations in Oncomelania hupensis after molluscicide treatment: implication for future molluscicide development. Parasitol Res. 2016:115:4139-52

19. Yuan Y, Xu XJ, Dong HF, Jiang MS, Zhu HG. Transmission control of schistosomiasis japonica: implementation and evaluation of different snail control interventions. Acta Trop. 2005;96:191-7.

20. Huang YX, Sun LP, Hong QB, Gao Y, Zhang K, Yang K, Wu F. Evaluation of molluscicidal effect of Qiangluocide powder by dusting fields. Chin J Schisto Control. 2003:15:434-8, (in Chinese).

21. Huang $Y X$, Hong QB, Sun LP, Wu F, Xi WP, Cai G. Studies on molluscicidal effect of niclosamide ethanolamine salt dustable powder against Oncomelania hupensis. Chin J Schisto Control. 2003;15:434-8, (in Chinese).

22. Fang $Y M$, Huang $Y X$. Application of niclosamide ethanolamine salt dustable powder. Chin J Schisto Control. 2007;19:398, (in Chinese)

23. Xing YT, Dai JR, Dai Y, Yang ZK, Wang F, Liang XT, Ma B, Qu GL, Wang W, Liang YS. Preparation and molluscicidal effect of $5 \%$ niclosamide ethanolamine granules. Chin J Schisto Control. 2013:25:473-6, (in Chinese).

24. Wu RF, Xiao M, Dai JR. Molluscicidal effect of $5 \%$ niclosamide ethanolamine granules against Oncomelania hupensis in a marshland field. Chin J Schisto Control. 2014;26:573-5, (in Chinese).

25. Feng XG, Li BG, Li WB, Wu MS, Huang NB, Zhang Y, Xiong MT, Mu LX, Tian SH, Li P, Shen MF, Wang LF, Song J, Sun JY. Molluscicidal effect of 5\% powder of niclosamide ethanolamine salt granules (NEG) in field of mountainous areas in Yunnan Province. Chin J Schisto Control. 2015;27:12933, (in Chinese).

26. Tang WJ, Sun HC, Liu RH. Efficiency trials of plant molluscicide "Luowei"on killing Oncomelania hupensis. J Yangtze River Sci Res Inst. 2010;27:105-8, (in Chinese).

27. Jia TW, Sun LP, Hong QB, Tao B, Cai JX, Li YS, Lin DD, Yu XL, Zhou XN. Field evaluation of a novel plant molluscicide "Luo-Wei" against Oncomelania hupensis I Molluscicidal effect by the spraying method in lake and marshland regions. Chin J Schisto Control. 2013;25:125-8, (in Chinese)

28. Zhang ZH, Fang R, Yu B, Liu ZS, Zhao ZJ, Xu XW, Huang XL, Jia TW. Field evaluation of a novel plant molluscicide "Luo-wei" against Oncomelania hupensis snails II Molluscicidal effect in the field of lake areas in Hanchuan City, Hubei Province. Chin J Schisto Control. 2013;25:481-4, (in Chinese). 
29. Zhou Y, Wang ZM, Zhang B, Xie DB, Mei ZZ, Jia TW, Hong QB, Sun LP. Field evaluation of a novel plant molluscicide "Luo-wei" against the snail Oncomelania hupensis III Molluscicidal effect by spraying method in hilly regions. Chin J Schisto Control. 2013;25:495-7, (in Chinese).

30. Huang NB, Li BG, Li WB, Feng XG, Xiong MT, Li L, Mu LX, Tian SH, Li P, Song ZZ, Jia TW. Effect of a novel plant molluscicide "Luo-wei" against Oncomelania hupensis in plateau mountain areas. Chin J Schisto Control. 2013;25:495-7, (in Chinese).

31. Sun HC, Liu XL, Liu RH. Research on environmental biosafety of "Luowei"powder (TDS), a plant molluscicide. J Yangtze River Sci Res Inst. 2010;27:102-4, (in Chinese)

32. Yi P, Peng C, Li S. Study on acute inhalation toxicity of Luowei, a plant molluscicide. Chin J Schisto Control. 2016;28:79-80, (in Chinese).

33. Yin FP, Jia XB. Control effect of $4 \%$ TDS DP against Pomacea canaliculata. Pest Sci Admin. 2016;37:54-6, (in Chinese).

34. Cui GY, Wang SP, Cheng HB, He X, Lvqiu SJ, Huang CM. Screening of molluscacidal microorganisms against Oncomelania hupensis and their effect. Chin J Parasitol Parasit Dis. 2015;33:234-6, (in Chinese).

35. Cui GY, Wang SP, Cheng HB, Wei H, He X, Lvqiu SJ, Huang CM. Screening and molluscicidal activity of microorganism against Oncomelania hupensis. Chin J Zoon. 2015;31:109-12, (in Chinese).

36. Cheng WT, Zhou YB, Pan X, Song XX, Jiang QW. Advances in researches of molluscicidal microorganism against Oncomelania hupensis. Chin J Schisto Control. 2016;28:103-17, (in Chinese).

37. Xu J, Bergquist R, Qian YJ, Wang Q, Yu Q, Peeling R, Croft S, Guo JG, Zhou XN. China-Africa and China-Asia collaboration on schistosomiasis Control: SWOT analysis. Adv Parasitol. 2016;92:435-66.

38. Xu J, Yu Q, Tchuenté LA, Bergquist R, Sacko M, Utzinger J, Lin DD, Yang K, Zhang LJ, Wang Q, Li SZ, Guo JG, Zhou XN. Enhancing collaboration between China and African countries for schistosomiasis control. Lancet Infect Dis. 2016;16:376-83.

39. Rollinson D, Knopp S, Levitz S, Stothard JR, Tchuem Tchuenté LA, Garba A, Mohammed KA, Schur N, Person B, Colley DG, Utzinger J. Time to set the agenda for schistosomiasis elimination. Acta Trop. 2013;128:423-40.

\section{Submit your next manuscript to BioMed Central and we will help you at every step:}

- We accept pre-submission inquiries

- Our selector tool helps you to find the most relevant journal

- We provide round the clock customer support

- Convenient online submission

- Thorough peer review

- Inclusion in PubMed and all major indexing services

- Maximum visibility for your research

Submit your manuscript at www.biomedcentral.com/submit

) Biomed Central 